\title{
Karakteristik Lingkungan Fisik yang Mempengaruhi Pengelolaan Air berdasarkan Water Sensitive Urban Design di Kelurahan Tambak Sarioso
}

\author{
I Made Sukma Pradipta dan Adjie Pamungkas \\ Jurusan Perencanaan Wilayah dan Kota, Fakultas Teknik Sipil dan Perencanaan, \\ Institut Teknologi Sepuluh Nopember (ITS) \\ Jl. Arief Rahman Hakim, Surabaya 60111 Indonesia \\ e-mail: adjie.difi@gmail.com
}

\begin{abstract}
Abstrak-Kelurahan Tambak Sarioso sebagai salah satu wilayah yang terletak di Kawasan Startegis Ekonomi Teluk Lamong belum terlayani kebutuhan air secara merata. Selain kurangnya ketersediaan air, terdapat persoalan air terkait genangan/banjir rob. Berbagai upaya telah dilakukan untuk mengurangi persoalan air tersebut namun belum optimal. Konsep Water Sensitive Urban Design merupakan pendekatan rancang kota yang dapat mengurangi persoalan ketersediaan dan banjir. Penelitian ini bertujuan mengkaji karakteristik lingkungan fisik yang mempengaruhi pengelolaan air berdasarkan Water Sensitive Urban Design (WSUD) di Kelurahan Tambak Sarioso sebagai bahan dalam perumusan Prinsip Water Sensitive Urban Design yang berpeluang diterapkan di wilayah penelitian. Artikel ini merupakan bagian dari penelitian mengenai Prinsip Water Sensitive Urban Design Kawasan Pesisir di Kelurahan Tambak Sarioso. Tahapan peneletian ini menggunakan walkthrough analysis. Hasil penelitian meunujukkan bahwa karakteristik lingkungan fisik yang mempengaruhi pengelolaan air berdasarkan Water Sensitive Urban Design di Kelurahan Tambak Sarioso terdapat persoalan air seperti genangan/banjir akibat rob dan hujan dan kurangnya pelayanan air.
\end{abstract}

Kata Kunci-Sensitive Urban Design, Tambak Sarioso, Walkthrough Analysis, Water.

\section{PENDAHULUAN}

$\mathrm{K}^{\mathrm{o}+x_{2}}$ OTA Surabaya sebagai ibukota Propinsi Jawa Timur meruapakan suatu pusat kegiatan yang didiami oleh 2.930.520 jiwa [1]. Pusat kegiatan yang terdapat di pesisir barat daya Kota Surbaya diantaranya adalah kawasan industri dan pergudangan, pertanian lading garam, permukiman serta pelabuhan. Sebagai salah satu pusat kegiatan, kawasan ini rentan terhadap berbagai risiko yang diakibatkan oleh persoalan terkait pengelolaan air. [2]

Kelurahan Tambak Sarioso merupakan salah satu kelurahan yang terletak di Kecamatan Asemrowo, Kota Surabaya. Wilayah ini menjadi salah satu kawasan aglomerasi dari pengembangan Pelabuhan Teluk Lamong. Jumlah penduduk Kelurahan Tambak Sarioso tahun 2011-2015 mengalami pertumbuhan dari 4.043 jiwa menjadi 6.978 jiwa dengan diikuti kebutuhan air yang cukup besar. [3]

Kebutuhan air di Kelurahan Tambak Sarioso sebesar 357,59 kiloliter per hari/hektare. Sedangkan rata-rata produksi air yang diberikan PDAM Kota Surabaya 23,1 kiloliter per hari/hectare [4]. Hal ini menunjukkan PDAM Kota Surabaya belum mampu memenuhi kebutuhan air di kelurahan tersebut, sehingga untuk memenuhi kebutuhan air bersih beberapa industri/depo pergudangan membeli dari truk tangki. [5]

Permasalahan lainnya di Kelurahan Tambak Sarioso adalah banjir rob yang terjadi di pesisir Kota Surabaya. Banjir rob menggenangi permukiman setinggi $50 \mathrm{~cm}$ serta meluber hingga ke jalan yang menyebabkan ketidaknyamanan dalam berlalu lintas [6]. Banjir rob yang menggenangi jalan raya ini juga menyebabkan puluhan sepeda motor mogok serta banyak motor yang mengalami kerusakan. Jika hal ini terus menerus terjadi, bukan tidak mungkin Kota Surabaya khususnya wilayah bagian utara tidak lagi menjadi pusat kegiatan industri dan pergudangan, permukiman, dan lain-lain.

Berbagai upaya telah dilakukan untuk mengatasi kurangnya ketersediaan air dan penanggulangan terhadap banjir rob yang telah dilakukan oleh pemerintah dan masyarakat. Pemerintah telah melakukan program penyediaan fasilitas air bersih untuk melayani kebutuhan air bersih di wilayah penelitian. Sementara itu, berdasarkan persoalan banjir rob, pemerintah telah melakukan normalisasi di sejumlah titik dengan membuat waduk mini maupun memperbanyak sumur biopori untuk menyerap air [7]. Namun, upaya-upaya tersebut belum efektif dalam memecahkan persoalan air di wilayah penelitian. Dengan keterbatasan yang ada diperlukan suatu pendekatan baru terkait pengelolaan air di Kelurahan Tambak Sarioso. Pendekatan tersebut melalui rancang kota, mengingat upaya ini belum menjadi perhatian oleh stakeholders terkait. Diperlukan upaya lain yaitu dengan menggunakan konsep Water Sensitive Urban Design untuk mengurangi persoalan air yang terjadi di Kelurahan Tambak Sarioso. Konsep ini digunakan karena merupakan konsep perancangan kota yang mengintegrasikan pengelolaan air kedalam proses pembangunan perkotaan [8].

Berdasarkan pemaparan masalah diatas mengindikasikan bahwa usaha-usaha dalam mengurangi persoalan air di perkotaan belum maksimal. Maka dalam menangani persoalan air seharusnya melihat karakteristik lingkungan fisik yang mempengaruhi pengelolaan air berdasarkan Water Sensitive Urban Design di Kelurahan Tambak Sarioso. 


\section{METODE PENELITIAN}

\section{A. Metode Pengumpulan Data}

Metode pengumpulan data yang diguankan dalam penelitian ini adalah dengan teknik survei primer dan survei sekunder. Survei primer melalui observasi pada wilayah penelitian yang telah dibagi menjadi 18 blok sesuai dengan karakteristik yang sama dan teknik area sampling dengan pengambilan acak [9] serta menggunakan alat rekam berupa kamera. Survei sekunder dilakukan dengan survei literatur berupa buku, jurnal, pedoman atau perundang-undangan pengelolaan air, profil kelurahan dan draft rencana pengembangan yang membahas konsep Water Sensitive Urban Design dan Kelurahan Tambak Sarioso. Berikut di bawah ini peta pembagian blok penelitian.

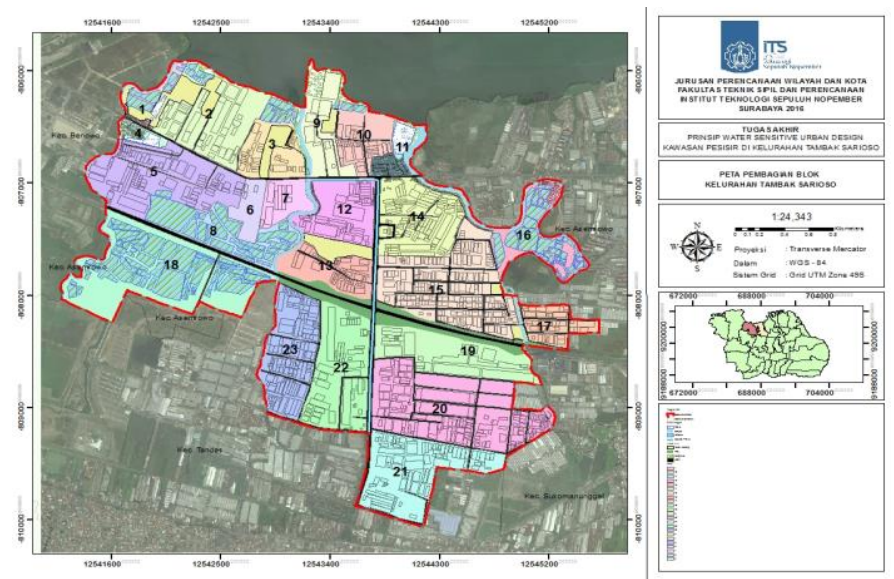

Gambar 1 Peta pembagian blok penelitian di Kelurahan Tambak Sarioso

\section{B. Metode Analisis}

Metode analisis yang digunakan dalam penelitian ini adalah teknik analisis Walkthrough Analysis. Analisis tersebut merupakan analisis deskriptif mengenai penggambaran kondisi wilayah. Analisis ini mengkaji kualitas perkotaan yang dilakukan dengan cara berjalan melalui penggal-penggal jalan dan mengamati serta merasakan kesan di sepanjang jalan melalui rekaman gambar eksisting dari wilayah penelitian. Teknik ini menggunakan metode visual grafis dalam melakukan pengamatan pada saat merekam objek [10]. Sehingga dalam pembahasannya, analisis ini menggunakan deskriptif kualitatif dalam menyampaikan informasi gambar yang tersusun berdasarkan lokasi-lokasi perjalanan. Teknik ini dilakukan dengan cara Linier Side View yaitu dengan menggambarkan suasana sebuah area melalui jalur terkait. Pandangan yang ditampilkan ialah pandangan berurutan (serial view). Pandangan tersebut memperlihatkan simulasi mengenai bagaimana para pejalan kaki bergerak dan melangkah ke depan; serta memandang ke samping untuk menikmati dan melihat kondisi di sekeliling [11].

\section{HASIL DAN DISKUSI}

Dalam mengidentifikasi karakteristik lingkungan fisik yang mempengaruhi pengelolaan air berdasarkan Water Sensitive Urban Design di Kelurahan Tambak Sarioso dengan menggunakan teknik analisis Walkthrough Analyisis, yaitu dengan mengambil gambar yang sesuai dengan variabel prinsip Water Sensitive Urban Design pada tiap blok kemudian diintepretasikan dengan deskriptif kualitatif sesuai visualisasi gambar tersebut. Berikut tabel hasil pengamatan karakteristik lingkungan fisik yang mempengaruhi pengelolaan air berdasarkan Water Sensitive Urban Design pada 18 blok terpilih.

\section{Indikator ketersediaan air}

Karakteristik pada indikator ketersediaan air antara lain jenis air permukaan, curah hujan, infiltrasi, limpasan air, dan topografi. Hampir seluruh karakteristik pada jenis air permukaan pada tiap blok sama yaitu berupa sungai, tambak, rawa, dan jaringan drainase.
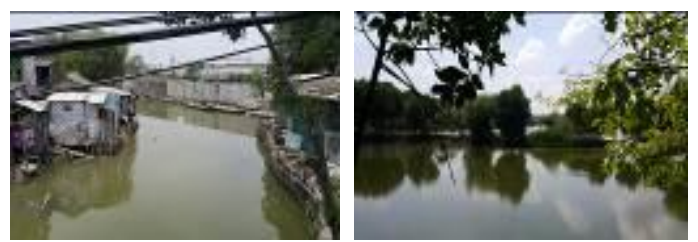

Gambar 2 Kondisi jenis air permukaan di Kelurahan Tambak Sarioso

Curah hujan berfluktuasi selama 5 tahun terakhir menyebabkan ketidakpastian keberadaan air permukaan di wilayah penelitian. Infiltrasi yang dipengaruhi oleh jenis tanah di wilayah penelitian yang berupa jenis tanah alluvial hidromorf dan grumusol kelabu tua yang bersifat lempung dan tidak peka tehadap penyerapan air menyebabkan peningkatan risiko genangan saat hujan. Limpasan air dimana seluruh blok penelitian menunjukkan $70 \%$ mengalir diatas permukaan dan $30 \%$ lainnya terserap. Topografi rendah dengan kelerangan 0-2\% serta berada 3 meter diatas permukaan air laut yang menyebabkan wilayah ini rentan terhadap kenaikan muka air laut yang menyebabkan banjir rob.

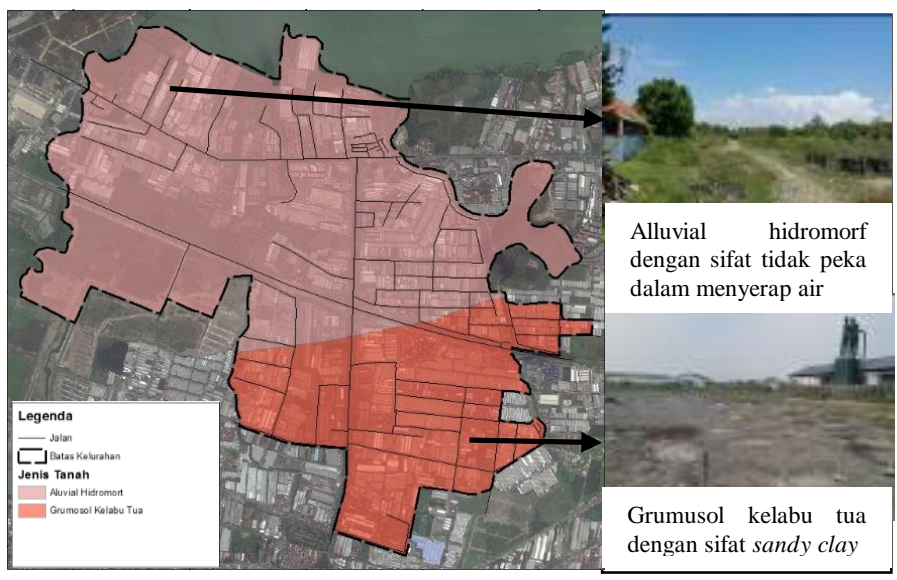

Gambar 3 Kondisi jenis tanah di Kelurahan Tambak Sarioso

\section{Indikator permintaan air}

Karakteristik pada indikator permintaan air antara lain penggunaan lahan kepadatan bangunan. Penggunaan lahan pada tiap blok berbeda-beda, namun hampir sebagian besar di dominasi oleh penggunaan lahan industri/depo pergudangan yaitu sebesar 429 hektare, perumahan 18 hektare, ruang terbuka hijau 18,037 hektare, perdagangan dan jasa 1,4 hektare dan 
lain-lain. Adapun penggunaan lahan dominasi perumahan berada pada blok 1, blok 4, dan blok 11, dominasi blok industri/depo pergudangan berada pada blok 2 , blok 5 , blok 6 , blok 9 , blok 10 , blok 13, blok 15, blok 19, blok 20, blok 21, blok 22, dan blok 23. Terakhir untuk dominasi ruang terbuka berada pada blok 8 , blok 16, dan blok 18. Berikut dibawah ini merupakan tabel penggunaan lahan di Kelurahan Tambak Sarioso.

Tabel 1

Penggunaan Lahan di Kelurahan Tambak Sarioso

\begin{tabular}{clc}
\hline No & Penggunaan Lahan & $\begin{array}{c}\text { Kelurahan } \\
\text { Tambak Sarioso } \\
\text { Luas (Ha) }\end{array}$ \\
\hline 1 & Perumahan & 18 \\
2 & Perdagangan/Jasa & 1,4 \\
3 & Fasilitas Umum & 8,85 \\
4 & Industri/Depo & 429 \\
& Pergudangan & 18,037 \\
5 & Ruang Terbuka Hijau & 92 \\
6 & Tambak & 23 \\
7 & Sungai & 10 \\
8 & Mangrove & 30 \\
9 & Tanah Kosong & 6 \\
10 & Rawa & 60 \\
11 & Jalan & 696,287 \\
\multicolumn{2}{c}{ Jumlah }
\end{tabular}

Sumber : Profil Kelurahan Tambak Sarioso, 2016

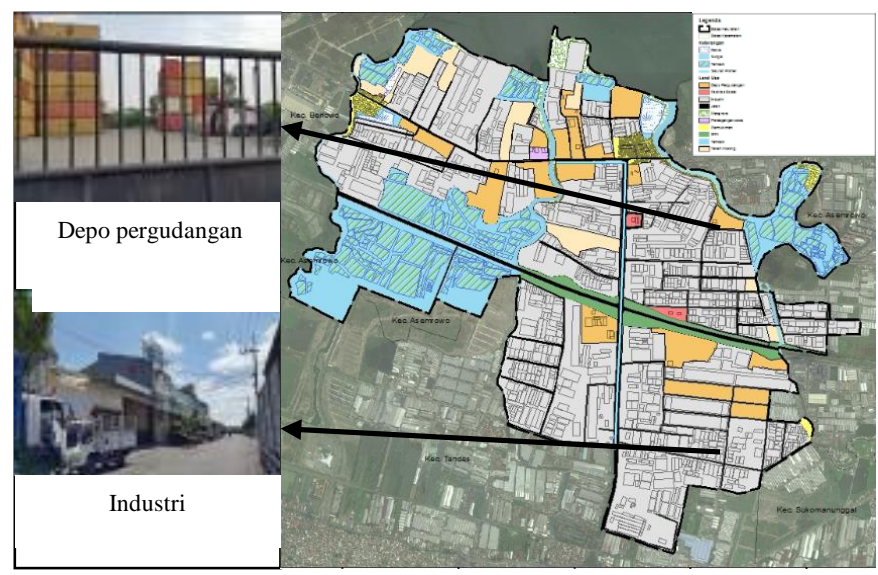

Gambar 4 Kondisi penggunaan lahan di Kelurahan Tambak Sarioso

Karakteristik kepadatan bangunan tiap bloknya hampir sama yaitu pada kepadatan bangunan $>0,50$ seperti pada blok 2 , blok 5 , blok 13, blok 15 , blok 19, blok 20, blok 21, blok 22, dan blok 23. Sementara, karakteristik kepadatan bangunan rendah pada blok 1, blok 8, blok 16, dan blok 18. Hal ini menunjukkan bahwa blok-blok dominasi industri membutuhkan air yang cukup banyak. Berikut tabel karakteristik kepadatan bangunan di Kelurahan Tambak Sarioso.

Berdasarkan hasil tabel 2, diketahui bahwa penggunaan lahan dan kepadatan bangunan mempengaruhi kebutuhan air pada blok-blok yang memiliki tingkat kepadatan bangunan tinggi dengan penggunaan lahan dominasi industri/depo pergudangan.
Tabel 2

Kepadatan Bangunan di Kelurahan Tambak Sarioso

\begin{tabular}{cccc}
\multicolumn{4}{c}{ Kepadatan Bangunan di Kelurahan Tambak Sarioso } \\
\hline \hline $\begin{array}{c}\text { Kelurahan } \\
\text { Tambak } \\
\text { Sarioso }\end{array}$ & $\begin{array}{c}\text { Luas Area } \\
\text { Terbangun (Ha) }\end{array}$ & Luas Blok (Ha) & $\begin{array}{c}\text { Rasio } \\
\text { Kepadatan } \\
\text { Terbangun }\end{array}$ \\
\hline Blok 1 & 0,89 & 13,5 & 0,06 \\
Blok 2 & 30,13 & 51,5 & 0,58 \\
Blok 4 & 2,62 & 6,2 & 0,42 \\
Blok 5 & 46,90 & 59 & 0,79 \\
Blok 6 & 0,94 & 10,6 & 0,08 \\
Blok 8 & 0 & 35 & 0 \\
Blok 9 & 11,20 & 29,7 & 0,38 \\
Blok 10 & 10,74 & 23,2 & 0,46 \\
Blok 11 & 4,59 & 13,3 & 0,34 \\
Blok 13 & 20,82 & 33 & 0,63 \\
Blok 15 & 53,67 & 77,6 & 0,69 \\
Blok 16 & 1,85 & 32,3 & 0,05 \\
Blok 18 & 0 & 92,61 & 0 \\
Blok 19 & 26,51 & 51,14 & 0,51 \\
Blok 20 & 60,17 & 83,20 & 0,72 \\
Blok 21 & 37,95 & 53,05 & 0,71 \\
Blok 22 & 39,37 & 53,57 & 0,73 \\
Blok 23 & 39,88 & 45,23 & 0,88 \\
\hline \hline
\end{tabular}

Sumber : Profil Kelurahan Tambak Sarioso, 2016

Indikator infrastruktur pengelolaan air berdasarkan Water Sensitive Urban Design (WSUD)

Karakteristik pada indikator infrastruktur pengelolaan air antara lain bioretensi, sumur kering, sabuk hijau, legokan berumput, atap hijau, tong hujan, parit infiltrasi, dan paving permeable. Pada karakteristik bioretensi, sumur kering, tong hujan seluruh blok tidak ada, sabuk hijau atau lebih dikenal dengan lansekap jalan dan parit infiltrasi hampir seluruh blok terdapat infrastruktur ini. Atap hijau hanya terdapat pada blok 4 namun tidak semua bangunan pada blok ini terpasang atap hijau. Sementara untuk paving permeable terdapat pada blok 1, blok 2 , blok 4, blok 5, blok 6, blok 9, blok 10, blok 11, blok 13, blok 15, blok 16, blok 19, blok 20, blok 21, blok 22, dan blok 23. Hal tersebut menggambarkan bahwa adanya peluang dalam penerapan Konsep Water Sensitive Urban Design dalam mengurangi persoalan isu air di wilayah penelitian. Berikut beberapa contoh gambar infrastruktur pengelolaan air berdasarkan WSUD di Kelurahan Tambak Sarioso.

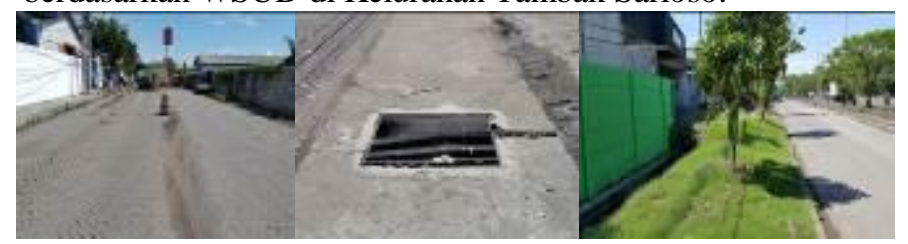

Gambar 5 Kondisi elemen WSUD di Kelurahan Tambak Sarioso

\section{Indikator guna lahan}

Karakteritik pada indikator guna lahan antara lain internal dan eksternal kapling perumahan, internal dan eksternal kapling fasilitas sosial, internal dan eksternal kapling industri/depo pergudangan. Untuk karakteristik yang di dominasi internal dan ekternal kapling perumahan berada pada blok 1, blok 4, blok 11, dan blok 16. Kemudian karakteristik yang di dominasi internal dan eksternal kapling industri/depo pergudangan berada pada blok 2, blok 5, blok 6, blok 8, blok 9, blok 10, blok 13, blok 15, blok 19, blok 20, blok 21, blok 22, dan blok 23. Sedangkan 
untuk karakteristik internal dan eksternal kapling fasilitas sosial terdapat di sebagian kecil di blok 1. Pada karakteristik guna lahan ini menggambarkan peluang penerapan dalam peletakkan infrastruktur pengelolaan air berdasarkan Water Sensitive Urban Design (WSUD).

\section{Indikator sirkulasi/parkir}

Karakteristik pada indikator sirkulasi/parkir antara lain jenis material sistem sirkulasi/parkir, ketersediaan vegetasi, ketersediaan jaringan drainase, ketersediaan fasilitas penyaring dan fungsi jalan. Karakteristik jenis material sistem sirkulasi/parkir tiap blok berbeda-beda antara lain jenis material yang diperkeras dengan beton berada pada blok 11, blok 19, blok 20, blok 21, blok 22 dan blok 23. Karakteristik jenis material campuran berada pada blok 1, blok 2, blok 4, blok 5, blok 6, blok 9, blok 10, blok 13, blok 15 dan blok 16 . Karakteristik jenis material mudah menyerap air berada pada blok 8 dan blok 18. Ketersediaan vegetasi hampir semua blok terdapat vegetasi berupa lansekap jalan baik berfungsi sebagai penyerap karbon, perindang maupun penyerap air permukaan. Karakteristik ketersediaan jaringan drainase hampir di seluruh blok terdapat jaringan drainase hanya di blok 8 dan blok 18 tidak terdapat jaringan drainase. Selain itu kondisi jaringan drainase di blok 1, blok 2, blok 4, blok 5, dan blok 23 kurang baik. Hal ini dikarenakan sambungan drainase tidak tersambung hingga ke sistem drainase primer selain itu kondisi yang kurang baik, sehingga menyebabkan genangan/banjir ketika hujan turun.
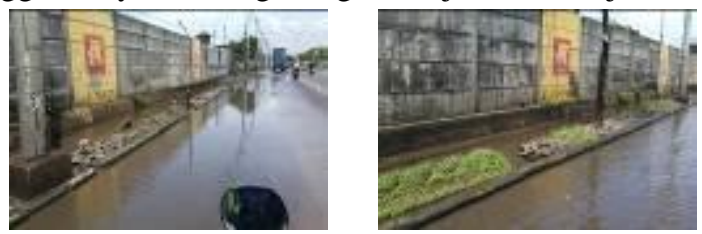

Gambar 6 Kondisi jaringan drainase di Kelurahan Tambak Sarioso

Karakteristik fasilitas penyaring hampir di seluruh blok terdapat hanya di blok 8 dan blom 18 tidak terdapat. Karakteristik fasilitas penyaring di wilayah penelitian berupa paving permable dan saringan sampah (filter trap). Karakteristik fungsi jalan berbeda-beda antara lain fungsi jalan lokal-arteri berada pada blok 1, blok 2, blok 4, blok 5, blok 6 blok 9, blok 10 , blok 11, blok 13, blok 15, blok 19, blok 20, blok 21, blok 22 . Karakteristik fungsi jalan lokal pada blok 16 dan blok 23 . Sementara itu, fungsi jalan tol berada pada blok 8 dan blok 18 . Hal ini menggambarkan peluang peletakkan infrastruktur pengelolaan air berdasarkan Water Sensitive Urban Design (WSUD) yang bervariasi.

\section{Indikator ruang terbuka}

Karakteristik pada indikator ruang terbuka antara lain ketersediaan strip penyangga, ketersediaan koridor drainase, ketersediaan fasilitas resapan. Karakteristik strip penyangga seluruh blok terdapat strip penyangga. Kemudian, karakteristik ketersediaan koridor drainase pada ruang terbuka hampir semua terdapat kecuali pada blok 8 dan blok 18. Karakteristik fasilitas resapan terdapat di hampir seluruh blok kecuali di blok 8 dan blok 18. Hal ini menggambarkan bahwa pada blok 8 dan blok 18 rentan terhadap genangan ketika hujan turun. Berikut isualisasi peta dari karakteristik lingkungan fisik yang mempengaruhi pengelolaan air berdasarkan WSUD di Kelurahan Tambak Sarioso.

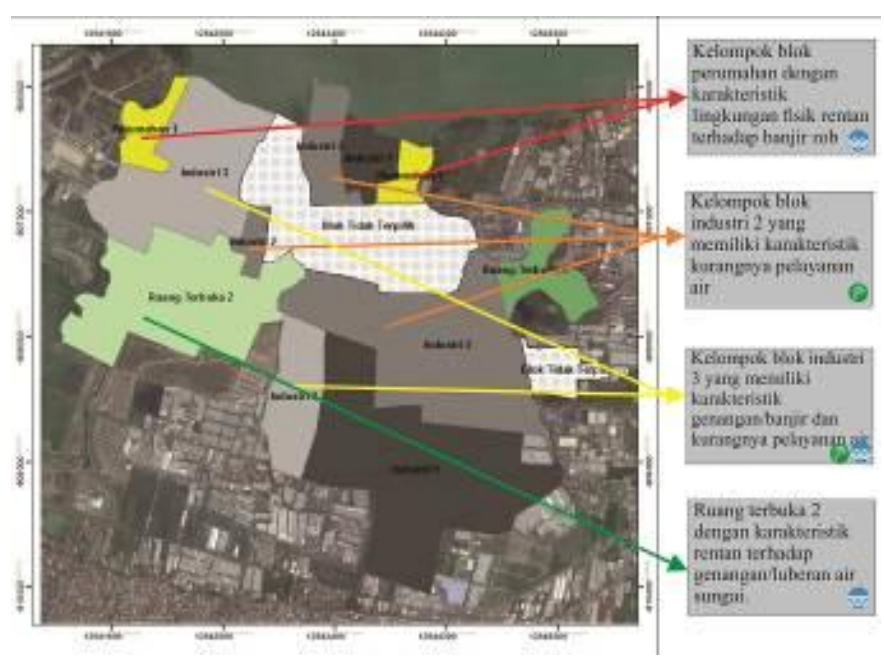

Gambar 7 Karakteristik lingkungan fisik yang mempengaruhi pengelolaan air berdasarkan WSUD di Kelurahan Tambak Sarioso

\section{KESIMPULAN}

Berdasarkan hasil analisis dan pembahasan yang telah dilakukan dalam penelitian, maka dapat disimpulkan bahwa blok-blok penelitian masuk dalam 3 tipologi kelompok blok dengan karakteristik yang sama seperti 1) kelompok blok perumahan dengan karakteristik lingkungan fisik rentan terhadap banjir rob. 2) kelompok blok industri yang terbagi menjadi 3 karakteristik seperti industri 1 dengan karakteristik pengelolaan air yang sudah baik, kelompok blok industri 2 yang memiliki karakteristik kurangnya pelayanan air, kelompok blok industri 3 yang memiliki karakteristik genangan/banjir dan kurangnya pelayanan air. 3) kelompok blok ruang terbuka yang terbagi menjadi ruang terbuka 1 dengan karakteristik sudah baik pengelolaan airnya dan ruang terbuka 2 dengan karakteristik rentan terhadap genangan/luberan air sungai.

\section{DAFTAR PUSTAKA}

[1] Dinas Kependudukan dan Pencatatan Sipil Kota Surabaya. 2015 : Kota Surabaya

[2] RZWP Kota Surabaya. 2011 : Kota Surabaya

[3] RZWP Kota Surabaya. 2011 : Kota Surabaya

[4] RDTR UP XI Tambak Oso Wilangun

[5] Draft RTR KSE Teluk Lamong

[6] Radio Republik Indonesia. 26 Juni 2013

[7] Detiknews. 24 Agustus 2014

[8] Barton, A.B., A.J. Smith, S. Maheepala and O. Barron (2009) Advancing IUWM through an understanding of the urban water balance $8^{\text {th }}$ World IMACS / MODSIM Congress, Cairns, Australia 13-17 July 2009 http://mssanz.org.au/modsim09

[9] Sugiyono. 2013. Metode Penelitian Kuantitatif Kualitatif dan $R \& D$. Alfabeta. Bandung, $372 \mathrm{hlm}$.

[10] Manatü, M. 2006. Urban Design Toolkit Third Edition. Wellington: Ministry for The Environment

[11] Cullen, G. 1961. Townscape. London: Architectural Press. 